\title{
Artigo
}

\section{O México olha para a América Latina e para a Ásia: novos desafios, nova estratégia?}

Mexico looks for Latin America and Asia: new challenges, new strategy?

DOI: $10.5752 /$ P.1809-6182.2016v13.n2.p86

Marcela Franzoni ${ }^{1}$

Carlos Eduardo Ferreira de Carvalho

\section{RESUMO}

Recebido em: 10 de março de 2016 Aprovado em: 25 de julho de 2016

As iniciativas mexicanas de reaproximação com a América Latina e de reposicionamento frente à China, motivadas por mudanças no cenário internacional e por dificuldades internas, têm gerado resultados fracos até aqui. A diplomacia econômica mexicana continua focada principalmente nos Estados Unidos e na OCDE.

Palavras-chave: Potência média. Diplomacia econômica. México.

\section{ABSTRACT}

Mexico's rapprochement initiatives with Latin America and facing China's relocation, driven by changes in the international scenario and internal difficulties have generated weak results so far. The Mexican economic diplomacy remains focused mainly in the United States and the OECD.

Keywords: Middle power. Economic diplomacy. Mexico.

1. Programa de Pós-Graduação em Relações Internacionais San Tiago Dantas (UNESP, UNICAMP e PUC-SP), Brasil. Graduada em Relaçôes Internacionais pela Universidade Federal de São Paulo e Mestranda no Programa de Pós-Graduação em Relaçôes Internacionais San Tiago Dantas (UNESP, UNICAMP e PUC-SP). orcid.org/00000002-7280-3318

2 Pontifícia Universidade Católica de São Paulo, Brasil. Professor do Departamento de Economia da Pontifícia Universidade Católica de São Paulo e do Programa de Pós-Graduação em Relaçóes Internacionais San Tiago Dantas (UNESP, UNICAMP e PUC-SP). orcid.org/0000-0002-8240-0061 


\section{Introdução}

O início do século XXI trouxe incentivos para o México reformular sua diplomacia econômica. O deterioramento da relação bilateral com os EUA, caso da política migratória, a crescente influência das potências médias no cenário internacional, em especial os BRICS, e a forte queda do PIB sob impacto da crise econômica norte-americana de 2008-2009 foram impulsos importantes para tentar recuperar espaços na América Latina e procurar inserção mais ativa na Ásia. O Foro do Arco do Pacífico Latino-americano, de 2007, a Comunidade de Estados Latino-americanos e Caribenhos (CELAC), de 2010, a Aliança do Pacífico, de 2012, e a Associação Estratégica com a China, de 2013, evidenciam a resposta mexicana a este cenário.

A expectativa era que a dependência dos Estados Unidos da América (EUA) poderia ser contrabalanceada com parcerias em outras regiôes, além de manter as relaçóes com países centrais. Buscava-se em especial retomar canais econômicos e políticos com a América Latina, onde o México encontrava-se ilhado pela ascensão de governos de centro-esquerda e pela liderança do Brasil.

$\mathrm{O}$ artigo discute os significados, as possíveis implicaçóes e o que se pode perceber até aqui como os resultados das iniciativas recentes na diplomacia econômica mexicana. Argumenta-se que indicam uma reformulação da sua inserção internacional, e não uma mudança de objetivos. O México mantém a orientação de abertura econômica, acordos de baixa formalização e foco na OCDE, mas quer acrescentar a esses eixos outras parcerias e a inserção na América Latina e na Ásia. Os resultados, porém, estão aquém do discurso.

\section{O México e seus desafios econômicos}

O México é tratado como potência média (MAIHOLD, 2014; NOLTE, 2006), como potência regional (SARKIS, 2010) e como país em desenvolvimento (COOPER; FLEMES, 2013). A dificuldade de tipificaçấo da sua posição internacional se deve a suas peculiaridades - dimensóes geoeconômicas e extensa fronteira com os Estados Unidos - e às escolhas feitas nos anos 1980, quando a opção pela aproximação com o vizinho e com a OCDE reorientou sua inserção internacional e impôs limites a sua atuação externa.

Para Nolte (2006), as potências médias localizam-se entre as grandes potências e as potências menores na hierarquia de poder internacional e podem exercer influência sistêmica ao atuar em instituiçôes internacionais. Para o autor, além das potências médias tradicionais, há as novas, que são primeiro potências regionais, com atuação prioritária em sua regiáo de influência, em que têm pretensão de liderança e definem a agenda, mas são também potências médias no âmbito global. Nessa linha, África do Sul, Brasil, Índia, México e Nigéria são consideradas novas potências médias, enquanto Austrália, Canadá, Nova Zelândia e Países Baixos são potências médias tradicionais (NOLTE, 2006).

As novas potências médias seriam definidas por critérios materiais - PIB, população, Forças Armadas - e também por categorias sociais, como capacidade de gerar entendimentos e de serem reconhecidas por outros Estados da regiáo e por outras potências regionais. Países com esse perfil podem criar equilíbrios frente aos EUA, estimulando coalizões diplomáticas alternativas. A influência de uma potência regional muitas vezes se formaliza no regionalismo, o qual se torna uma via importante para desempenharem papeis de maior peso no sistema internacional (NOLTE, 2006). 
Países considerados por Nolte (2006) como novas potências médias são definidos por Cooper e Flemes (2013) como poderes emergentes, originários do "Sul global" e que ganharam protagonismo no início do século XXI, exercendo considerável influência na economia e nas negociações internacionais. Para entendê-los, é necessário considerar suas respectivas regiôes, já que estabelecem conexóes entre a política regional e a política global (Cooper; Flemes, 2013). Os autores alertam, todavia, para o reducionismo de apontar a ascensão econômica chinesa como o único aspecto que estaria remodelando o sistema internacional, já que vários países demandam mais espaço na economia internacional e nas instituiçóes multilaterais. Mesmo que hoje alguns desses países estejam enfrentando problemas econômicos e instabilidade interna, são atores que não podem ser ignorados na atual configuraçáo da economia política internacional, continuando a demandar mais participação e instituiçôes que favoreçam seus projetos nacionais.

Apesar de a grande ênfase sobre as potências médias ser a atuação coletiva no sistema internacional, deve-se destacar que são países com perfis bastante distintos e, portanto, com dificuldades significativas para formalizar posturas comuns em questóes mais complexas. O caso mexicano é bastante peculiar. Como destaca Holbraad (1989), é histórica a dificuldade do país em lidar com a proximidade dos EUA, o que impacta no conceito teórico que deve ser utilizado para descrevê-lo. Assim, para que o México seja efetivamente um poder médio, segundo Pellicer (2006), seria necessário que adquirisse maior independência em relação aos EUA.

Havia grande expectativa nos anos 1980 com os resultados que o México obteria com a abertura econômica e a aproximação com os EUA, processos que culminaram com a assinatura do Tratado de Livre Comércio da América do Norte (TLCAN), em 1992, e o ingresso na Organização para a Coo- peração e Desenvolvimento Econômico (OCDE), em 1994, mas os resultados são bastante questionados (IBARRA, 2008). Apesar de o México ter se consolidado como destino do capital internacional e grande exportador de manufaturas, não consegue sustentar seu crescimento - de 2006 a 2014, o PIB cresceu apenas 2,3\% ao ano, taxa considerada baixa para o país da América Latina que tem maior participação no comércio mundial e que é o segundo maior receptor de investimentos externos na região (COMUNIDADE DE ESTADOS LATINO-AMERICANOS E CARIBENHOS, 2014). Além disso, o México se tornou muito dependente dos EUA, destino de $80 \%$ das exportaçôes e origem de quase $50 \%$ das importações do país (SECRETARÍA DE ECONOMÍA, 2015).

O segundo maior parceiro comercial do México é a China, mas com relevância só nas importações, que saltaram de 0,59\% do total em 1993 para $16,56 \%$ em 2014, enquanto a participação dos EUA caiu de $69,2 \%$ para $48,8 \%$ no mesmo período (SECRETARÍA DE ECONOMÍA, 2015). As exportaçôes para o mercado chinês continuam muito pequenas, apenas $1,5 \%$ do total. Essa forte assimetria sugere um arranjo produtivo em que o México é um elo entre a China e os EUA, importando bens chineses a serem revendidos para os EUA. Essa triangulação pode reforçar a posição mexicana na divisão internacional do trabalho, comum à de outras potências médias, em que os ganhos principais das vendas de manufaturados para os mercados líderes não são apropriados por suas próprias empresas, limitadas a formas variadas de elaboração apenas das fases finais da produção.

$\mathrm{Na}$ América Latina, é pequeno o comércio do México com os demais membros da Aliança do Pacífico - Chile, Colômbia, Peru -, apesar do acordo de livre-comércio e de facilitação dos investimentos. Os três países respondem por apenas 2,16\% das exportaçôes mexicanas e $0,84 \%$ das importa- 
çóes, números também muito baixos se considerado o conjunto da ALADI, $4,5 \%$ e $2,4 \%$ do total ou a América Central, 1,2\% e 1,07\% do total (SECRETARÍA DE ECONOMÍA, 2015).

O México continua sendo grande exportador de manufaturados $-91,5 \%$ do total das exportaçóes em dezembro de 2015, com o restante distribuído em $4 \%$ de petróleo e derivados, 3,3\% de agropecuários e 1,2\% de produtos extrativos; das importaçôes, $73,6 \%$ são bens de uso intermediário, $15,1 \%$ são bens de consumo, 11,2\% são bens de capital e 8,3\% são petroleiros (BANCO DE MÉXICO, 2016).

O perfil da balança comercial mexicana evidencia um país em desenvolvimento e com significativa participação em cadeias globais de valor devido ao alto índice de importaçóes de bens intermediários, que terão valor agregado internamente para serem reexportados. Nessa exportações, os insumos importados chegam a ser 2,9 vezes maiores que os nacionais (INSTITUTO DE ESTADÍSTICA Y GEOGRAFÍA, 2015), indicador de heterogeneidade estrutural, com baixa integração do setor manufatureiro exportador com o restante da economia. ${ }^{3}$ Essa debilidade econômica tem reflexos na estrutura social - 53,2\% da população mexicana vive abaixo da linha da pobreza (WORLD BANK, 2014).

É importante mencionar que muitos desses problemas - baixa internalização de tecnologia, volatilidade financeira e vulnerabilidade econômica frente à China são encontrados em outras potências médias. O caso mexicano é peculiar pela magnitude da dependência dos Estados Unidos, por ser uma plataforma de exportação de produtos manufaturados para os mercados centrais com

3. Vale destacar que não há mais distinção estatística entre o produto da indústria chamada de maquiladora e o conjunto da produção industrial, com o "Decreto para o fomento da indústria manufatureira, maquiladora e de serviços de exportaçáo", de 2006. De acordo com os últimos dados, de 2005 , 45\% das exportaçôes e $34 \%$ das importações mexicanas correspondiam a este setor. baixa integraçáo desse setor com o conjunto da economia e o baixo vínculo com países da sua regiáo. A vulnerabilidade da sua economia frente aos EUA e os índices sociais negativos questionam os resultados obtidos e estimulam pressões internas por mudanças.

\section{As iniciativas recentes: significados e possibilidades}

Alguns autores (GARZA; SCHIAVON; FLORES, 2010) apontam já estar presente no discurso do entáo presidente Vicente Fox (2000-2006) a intenção de diversificar as relaçóes comerciais. Sua política externa pretendia ampliar a participação do país nos fóruns internacionais e diminuir a vulnerabilidade econômica. O que era apontado como um "governo de mudança” pela troca histórica de partido político no poder, gerou resultados inesperados, não se configurando como um motor do desenvolvimento nacional. (GARZA; SCHIAVON; FLORES, 2010)

A reforma migratória que não avançou nos EUA, os efeitos da crise de 2008 na economia mexicana e as denúncias de espionagem sobre o entấo candidato à presidência Enrique Peña Nieto, em 2013, foram impulsos importantes para a revisão da política externa mexicana. Além de isso, com a ascensão de governos de centro-esquerda na América Latina, o país perdeu voz na regiáo e passou a ser apontado como pertencente de fato à América do Norte (ZICCARDI, 2011), critica reforçada pela manutençáo de parcerias econômicas focadas em livre-comércio.

Ao lado da busca de inserção na América Latina, o Pacífico passou a ser destacado como uma região articuladora da inserção internacional mexicana (RUIZ, 2010). Além do dinamismo da China e de outras economias asiáticas, pesou, nesse sentido, a migração de maquiladoras do México para a China, o fato deste país competir com produtos intermediários mexicanos e também ser importan- 
te quanto a sua capacidade financeira, quando, em 2012, o México lançava reformas institucionais, como a abertura do setor energético.

Nesse contexto, tanto o Foro do Arco do Pacífico latino-americano como a Aliança do Pacífico, segundo Ruiz (2010), têm como proposta central a coordenação de estratégias nacionais "para fora" com o gigante asiático. São iniciativas de cooperação econômica com foco comercial e que buscam compatibilizar os Tratados em vigor, além de aumentar investimentos. Ademais, não questionam a influência dos EUA no continente, sendo-lhe funcionais. Contrapóem-se então diretamente ao Mercosul na medida em que propóe a facilitação do comércio com parceiros externos (TURZI, 2014), internacionalizando os projetos nacionais liberais dos países membros.

O México mantém diversos interesses em participar desse processo. $\mathrm{O}$ tamanho do seu mercado interno, sua capacidade industrial e o grau de integração com a economia estadunidense poderia afirmá-lo como principal fornecedor de manufaturados e uma plataforma de produção e exportação (TURZI, 2014). Gardini e Malamud (2012) também apontam a Aliança do Pacífico como uma reação à radicalização ideológica de grande parte da América do Sul, apresentando outra proposta de regionalismo.

A CELAC é o principal espaço de diálogo entre o México e a América Latina. Criada em 2010, é uma instância multilateral para cooperação dos países latino-americanos mais ampla geograficamente que a União de Naçóes da América do Sul UNASUL, cujo protagonismo tornou-se um fator de isolamento e de caracterização do México como um aliado de Washington e não da América Latina (ZICCARDI, 2011). A diplomacia mexicana viu na CELAC possibilidades de articulação regional, em que se apresenta como um ator de equilíbrio, além de que a CELAC interessa à estratégia de inserção externa mexicana pela busca de articular a América
Latina com outras regióes do mundo, como se verificou nas cúpulas com a Uniāo Europeia (2013 e 2015) e com a China (2015).

Para uma presença mais global, o México também procurou aprofundar as relaçôes bilaterais com a China. Nos últimos anos, a cooperação se tornou mais intensa e evoluiu da Comissão Binacional Permanente México-China, de 2002, para a Associaçấo Estratégica Integral, de junho de 2013. Foram anunciados investimentos chineses na Petróleos Mexicanos (Pemex), a retirada de barreiras comerciais e a realização de fóruns para atrair investidores chineses.

Como muitas das iniciativas mencionadas estão em fase inicial, é difícil medir os efeitos que terão na inserção internacional mexicana. Já é possível afirmar, contudo, que tais resultados ainda se mostram fracos. Flores e Castillo (2012) argumentam que a concentração das relaçôes econômicas mexicanas nos Estados Unidos reduz os impactos das tentativas de diversificação, visto que esses esforços não diminuíram a dependência mexicana.

Mesmo a CELAC sendo apontada pela Secretaria de Relações Exteriores como um "[...] importante foro de diálogo y concertación política de la región", além de que "[...] permite consolidar el liderazgo de México [...]" (SECRETARÍA DE GOVERNACIÓN, 2016), falta o estabelecimento de acordos significativos, capacidade mexicana de exercer liderança efetiva e estabelecer consensos, além de avanços nas relaçôes econômicas, visto, por exemplo, o baixo índice comercial entre o México e a América Latina. Sua liderança no continente também está vinculada ao entendimento com o Brasil, economias não complementares. Ademais, o não comparecimento de Enrique Peña Nieto na Cúpula da CELAC, em janeiro de 2015, pode apontar para certo desinteresse mexicano da iniciativa, embora os problemas internos alegados para a ausência fossem relevantes - desaparecimento de 43 estudantes 
no estado de Guerrero e denúncias de corrupção.

O contexto internacional variável permite outros arranjos paralelos, como o MIST (México, Indonésia, Coréia do Sul e Turquia), proposto pelo Goldman Sachs em 2011. São países considerados potências médias, com população numerosa, renda média ou média alta, políticas econômicas bem avaliadas e perspectivas de crescimento econômico estáveis, e que ganham relevância com a desaceleração da economia chinesa e as baixas perspectivas de crescimento econômico do Brasil e da Rússia (MAIHOLD, 2014).

Deve-se argumentar também que, apesar de buscar reconhecimento como potência média de atuação global, o foco diplomático mexicano continua sendo os países do Norte e a inserção em seus mercados consumidores. A preferência por tratados de baixa formalização permite ao México engajar-se em várias regiōes do mundo sem questionar a influência dos EUA na economia política internacional. Em suma, o México não quer se distanciar da grande potência justamente por sua dependência comercial, de investimentos e da própria estrutura produtiva, voltada para as relaçóes com o mercado norte-americano.

Assim, é possível identificar três movimentos das relações econômicas internacionais do México que são complementares e que apontam para sua categorização de potência média com uma "política externa multivetorial" (MAIHOLD, 2014): primeiro, busca reinserir-se na América Latina e recolocar-se nos fóruns regionais, assim como parcerias mais focadas com países similares em estratégias de inserção internacional; segundo, o maior engajamento com a China evidencia-se mais como uma necessidade, visto a velocidade em que este país ganhou espaço na sua balança comercial e nos investimentos externos; por último, aposta simultaneamente em um contrapeso latino-americano à dependência que tem dos Estados Unidos, mas mantendo-se próximo aos projetos estratégicos da grande potência (Iniciativa Mérida - 2008 e Parceria Transpacífico - 2012) e da sua escolha preferencial pela OCDE.

\section{Algumas conclusões}

Apesar de hoje a diplomacia econômica mexicana contar com maiores instâncias de atuação, seus desdobramentos mostram as limitações da posição do México na busca por mais projeção no sistema internacional. As iniciativas para construçấo de liderança e de engajamento mais cooperativo com a América Latina, bem como para diversificar parcerias na Ásia, geraram resultados fracos: não há sinais de mudança na dependência econômica em relação aos EUA; não houve avanços significativos nas relaçôes com a América Latina e a Ásia; e o próprio México deu sinais de redução de interesse pelas iniciativas, como sugerido pela ausência do presidente Peña Nieto na cúpula da CELAC, em janeiro de 2015. As matrizes ideológicas das demais lideranças regionais e seus projetos de desenvolvimento sobrepóem-se ao desejado aumento da cooperação, tanto que a CELAC se mantém como uma instância pouco formalizada.

A reduçáo de espaços para a atuação das potências médias, com a desaceleraçáo econômica na China e a reconcentraçấo de poder nos Estados Unidos, parece ter feito prevalecer na diplomacia econômica mexicana a opção de manter o alinhamento preferencial com a grande potência. As iniciativas não foram abandonadas, mas estão em ritmo mais lento e menos ambicioso.

Uma política externa mais globalizada favorece a categorização do México como potência média, mas efetivar-se como tal e como potência regional dependeria de um engajamento mais autônomo em relação aos EUA, de forma a ter capacidade de estabelecer contrapesos regionais diante da 
influência da grande potência. A atual diminuição do espaço internacional e a escolha pelo TLCAN enfraquecem os resultados das suas iniciativas de aproximação com a regiáo, dificuldades que indicam um país em busca de estratégias que consigam articular seus interesses.

\section{Referências:}

BANCO DE MÉXICO. Balanza comercial de mercancias de México. [S. 1.]: BANXICO, 2016. Disponível em: <http:// www.banxico.org. $\mathrm{mx} /$ SieInternet $/$.do?accion=consultarCuadro\&idCuadro=CE125\&locale=es $>$ Acesso em: 10 fev. 2016.

COMUNIDADE DE ESTADOS LATINO-AMERICANOS E CARIBENHOS. Ingresso de investimento estrangeiro direto na América Latina e no Caribe por país receptor. 20082014. [S. 1.]: CEPAL, 2015. Disponível em: <http://www.cepal.org/sites/default/files/pr/files/tabla_ingresosied_pt_2015_. pdf.> Acesso em: 10 fev. 2016.

COOPER, A. F.; FLEMES, D.. Foreign Policy Strategies of Emerging Powers in a Multipolar World: na introductory review. Third World Quarterly, vol. 34, n. 6, 2013. Pp. 943-962. Disponível em: http://dx.doi.org/10.1080/01436597.2013.80 2501 Acesso em 26 de janeiro de 2016.

FLORES, Rafael Velázquez; CASTILLO, Juan Carlos. ¿¿Diversificación o concentración?: la política exterior de México en cifras 2006-2010. Revista de Relaciones Internacionales de la UNAM, n. 112, p. 133-163, jan./abr. 2012. Disponível em: <http://www.revistas.unam.mx/index.php/rri/article/ view/36044/32760.> Acesso em: 3 fev. 2016.

GARDINI, Andrés.; MALAMUD, Gian Luca. Has Regionalism Peaked?: The Latin American Quagmire and its Lessons.

The International Spectator: Italian Journal of International Affairs, Londres, v. 47, n. 1, 2012. Disponível em: <http:// www.tandfonline.com/loi/rspe20\#.Va99uflViko> Acesso em: 22 jul. 2015.

GARZA, H. (Ed.); SCHIAVON, J. A.; FLORES, R. V. (Coord.). Paradojas y paradigmas de la política exterior de México: 2000-2006. México: El Colégio de México - Centro de Investigación y Docencia Económica, 2010. Resenha de LÓPEZ, Jazmín Benítez. Paradigmas y paradojas de la política exterior de México. Revista de Relaciones Internacionales de la UNAM, n. 114, p. 155-164, Sep./Dic. 2012. Disponível em: <http://www.revistas.unam.mx/index.php/rri/article/ view/48995.> Acesso em: 18 jan. 2016.

HOLBRAAD, Carsten. Las potencias medias en la política internacional. México: Fondo de Cultura Económica, 1989.

IBARRA, Carlos. La paradoja del crecimiento lento de México. Revista CEPAL, v. 95, p. 83-102, ago. 2008. Disponível em: <http://www.cepal.org/es/publicaciones/11254-la-paradoja-crecimiento-lento-mexico $\geq$. Acesso em: 21 fev. 2016.

INSTITUTO DE ESTADÍSTICA Y GEOGRAFÍA. Manufacturas: Indústria Manufacturera, Maquiladora y de Servicios de Exportación (IMMEX). [S. 1.]: INEGRI, 2015. Disponível em: <http://www.inegi.org.mx/sistemas/bie/.> Acesso em: 6 jul. 2015.

MAIHOLD, Günther. Brics, Mist, Mikta: México entre poderes emergentes, potencias medias y responsabilidad global. Revista Mexicana de Política Exterior, Cidade do México, n. 100, jan./abr. 2014, p. 63-79. Disponível em: <http://revistadigital.sre.gob.mx/images/stories/numeros/n100/maihold. pdf.> Acesso em: 15 dez. 2015.

NOLTE, Detlef. Potencias regionales en la política internacional: conceptos y enfoques de análisis. German Institute of Global and Area Studies, Working Papers, n. 30, Oct. 2006. Disponível em: <http://repec.giga-hamburg.de/pdf/giga_06_ wp30_nolte.pdf.> Acesso em: 15 dez. 2015.

PELLICER, Olga. New powers for global change? Mexico: a reluctant middle power? FES Briefing Paper, June, 2006. Disponível em: <http://www.fes-globalization.org/publications/ FES_BP_Mexico_Pellicer_eng.pdf.> Acesso em: 23 mar. 2015. RUIZ, José Briceño. La iniciativa del Arco del Pacífico Latinoamericano: un nuevo actor en el escenario de la integración regional. Revista Nueva Sociedad, Buenos Aires, n. 228, jul./ ago. p. 44-59, 2010. Disponível em: <http://nuso.org/articulo/la-iniciativa-del-arco-del-pacifico-latinoamericano-un-nuevo-actor-en-el-escenario-de-la-integracion-regional/.> Acesso em: 23 jun. 2015.

SARKIS, M. O.. México en la estructura de poder latinoamericana: una aproximación desde el concepto de potencias medias. Revista Pléyade, Santiago, número 5, 2010, pp. 71-99. Disponível em: http://132.248.9.34/hevila/PleyadeSantiago/2010/no5/3.pdf. Acesso em 20 de março de 2016.

SECRETARÍA DE ECONOMÍA. Comercio exterior/información estadística y arancelaria. [S. 1.]: GOB, 10 mayo, 2015. Disponível em: <http://www.gob.mx/se/acciones-y-programas/comercio-exterior-informacion-estadistica-y-arancelaria?state=published.> Acesso em: 21 jan. 2016.

SECRETARÍA DE GOVERNACIÓN. Informe da Secretaría de Gobernación à Mesa Directiva de la Comisión Permanente del Honorable Congreso de la Unión. [S. l.]: SIL, 2016. Disponível em: <http://sil.gobernacion.gob.mx/Archivos/Documentos/2016/01/asun_3325212_20160120_1453311193. pdf.> Acesso em: 27 jan. 2016.

TURZI, M. Asia y la ¿̇(des) integración latinoamericana? Revista Nueva Sociedad, Buenos Aires, n. 250, mar./abr. p. 7887, 2014. Disponível em: <http://nuso.org/articulo/asia-y-la-desintegracion-latinoamericana/.> Acesso em: 23 jun. 2015.

WORLD BANK. México: Worldbank, 2014. Disponível em: $<$ http://data.worldbank.org/country/mexico.> Acesso em: 24 fev. 2016 
93 - Conjuntura Internacional - Belo Horizonte, ISSN 1809-6182, v.13 n.2, p.86 - 93, nov. 2016

ZICCARDI, N. S. México y América Latina: la vía multilate-

ral. In.: GONZÁLEZ, G.; PELLICER, O. (Org.) Los retos

internacionales de México: urgencia de uma mirada nueva.

Cidade do México: Siglo XXI Editores, 2011. 